\title{
Associations between obesity and cognitive impairment in the Chinese elderly: an observational study
}

This article was published in the following Dove Medical Press journal:

Clinical Interventions in Aging

\section{Qingtao Hou',* \\ Yang Guan ${ }^{1, *}$ \\ Weihua $\mathrm{Yu}^{2}$ \\ Xintong Liu' \\ Lihua $\mathrm{Wu}^{2}$ \\ Mingzhao $\mathrm{Xiao}^{3}$ \\ Yang Lü'}

'Department of Geriatrics, The First Affiliated Hospital of Chongqing Medical University, Chongqing, People's Republic of China;

${ }^{2}$ Department of Anatomy, Institute of Neuroscience, Chongqing Medical University, Chongqing, People's Republic of China; ${ }^{3}$ Department of Urology, The First Affiliated Hospital of Chongqing Medical University, Chongqing, People's Republic of China

*These authors contributed equally to this work
Correspondence: Yang Lü

Department of Geriatrics, The First Affiliated Hospital of Chongqing Medical University, I\# Youyi Road, Yuzhong District, Chongqing 400016, People's Republic of China

Tel $+86238901 \quad 1622$

Fax +86 23688|| 487

Email lyu_yang@126.com
Purpose: The aim of this study was to investigate the relationship between obesity and cognitive impairment in the Chinese elderly.

Patients and methods: Patients aged 60 years or above were enrolled from the Department of Geriatrics of The First Affiliated Hospital of Chongqing Medical University from March 2013 to May 2017. Mini-Mental State Examination scale was used to assess the cognitive function. Body mass index (BMI) and waist-hip ratio were used to classify obesity. Student's $t$-test, Mann-Whitney $U$-test, or chi-squared test was used to compare the data between participants with normal cognition and participants with cognitive impairment as appropriate. Univariate logistic regression models and multivariate logistic regression models were performed to explore the relationship between BMI or abdominal obesity and cognitive impairment.

Results: A total of 1,100 patients including 568 men and 532 women aged 60-98 years (median age 79 years) were enrolled. After adjusting for age, gender, smoking, drinking, education level, hypercholesterolemia, hypertension, and diabetes, overweight was significantly associated with a decreased risk of cognitive impairment $(\mathrm{OR}=0.458,95 \% \mathrm{CI}=0.298-0.703, P<0.001)$. After adjustment for age, education level, hypercholesterolemia, hypertension, and diabetes, abdominal obesity remained significantly associated with an increased risk of cognitive impairment $(\mathrm{OR}=1.532,95 \% \mathrm{CI}=1.037-2.263, P=0.032)$.

Conclusion: Overweight is associated with a decreased risk of cognitive impairment in the Chinese elderly, while abdominal obesity is associated with an increased risk of cognitive impairment independent of conventional sociodemographic, lifestyle, and health-related comorbid factors.

Keywords: body mass index, cognitive function, elderly, waist-hip ratio

\section{Introduction}

Aging of the population has become a public health problem following the rapid development of economy. Aging and age-related diseases have brought a huge economic burden to the whole society. Cognitive impairment and dementia are a kind of common age-related diseases. Epidemiological data show that dementia affects $5 \%-10 \%$ of people aged 65 years or older in higher-income countries. And the prevalence doubles every 5 years of age after age 65 . The annual age-specific incidences of dementia range from $0.1 \%$ at age $60-64$ to $8.6 \%$ at age $95 .{ }^{1}$ Cognitive impairment and dementia have become a major challenge to health and social care resources. Currently there is limited success on the treatment of cognitive impairment and dementia despite therapeutic advances. Therefore, the prevention is extremely important. Recent research suggests that preventing the risk factors of dementia is expected to reduce the risk ratio by $35 \% .^{2}$ Thus, identifying the potential risk factors of cognitive impairment 
and dementia, especially those modifiable risk factors, is an effective way to prevent cognitive decline.

Overweight and obesity have become a global epidemic, even among the elderly. According to the 2014 National Physique Monitoring Report, the prevalence rates of overweight and obesity in the Chinese elderly are $41.6 \%$ and $13.9 \%$ in 2014, which are $1.8 \%$ and $0.9 \%$ higher than those in 2010 , respectively. ${ }^{3}$ There is a growing body of researches investigating the relationship between obesity and cognitive impairment nowadays, but the results are conflicting mainly because of the different study populations. ${ }^{4-9}$ Meanwhile, there are limited data on the relationship between obesity and cognitive impairment independent of other metabolic risk factors in the elderly in People's Republic of China. Therefore, we conducted this study to investigate the relationship between obesity and cognitive impairment in the Chinese elderly by using comprehensive geriatric assessment data.

\section{Participants and methods Participants and data collection}

Patients aged 60 years or above were recruited from the Department of Geriatrics of The First Affiliated Hospital of Chongqing Medical University from March 2013 to May 2017. Patients with Parkinson's disease, intracranial tumor, severe psychosis, stroke, severe sensory damage, and severe complications were excluded. We also excluded patients involved in other studies. All the participants underwent a comprehensive geriatric assessment conducted by a trained nurse and confirmed by an experienced doctor. Data including social demographic characteristics, personal and family history, physical examination, laboratory tests, and cognitive function assessment were collected. Smoking was defined as having smoked at least one cigarette for over 6 months. Drinking was defined as having drunk more than once a week for at least 6 months. Height, weight, waist circumference, and hip circumference were manually measured. Body mass index (BMI) was calculated by the equation: BMI = weight $(\mathrm{kg}) /$ height (m). ${ }^{2}$ Waist-hip ratio (WHR) was calculated by the equation: $\mathrm{WHR}=$ waist circumference $(\mathrm{cm}) /$ hip circumference $(\mathrm{cm})$. Hypertension was defined as a systolic blood pressure higher than $140 \mathrm{mmHg}$ and/or a diastolic blood pressure higher than $90 \mathrm{mmHg}$ or taking antihypertensive drugs. Diabetes was defined according to the revised 1999 WHO criteria: fasting plasma glucose level $\geq 126 \mathrm{mg} / \mathrm{dL}(7.0 \mathrm{mmol} / \mathrm{L})$ and plasma glucose level $\geq 200 \mathrm{mg} / \mathrm{dL}$ (11.1 mmol/L) 2 hours after a $75 \mathrm{~g}$ oral glucose load. Participants taking antidiabetic medications were also recognized as diabetic patients. Hypercholesterolemia was defined as total cholesterol $>5.72 \mathrm{mmol} / \mathrm{L}$ or taking lipid-lowering drugs. All procedures performed in this study involving human participants were in accordance with the basic principles of the Declaration of Helsinki and had been approved by the Ethics Committee of The First Affiliated Hospital of Chongqing Medical University (Approved in 2012, No 15). No informed consent was available due to the retrospective design.

\section{Cognitive function assessment and obesity definition}

Mini-Mental State Examination (MMSE) scale was used to assess the cognitive function. The scores of MMSE range from 0 to 30, and higher scores indicate better cognitive function. Cognitive impairment was defined as a score $\leq 17$ for illiterates, $\leq 20$ for patients with primary school education, and $\leq 24$ for those with junior high school degree or above. ${ }^{10}$ BMI and WHR were used to classify obesity. BMI was classified into the following four categories: $<18.5 \mathrm{~kg} / \mathrm{m}^{2}$ (underweight), $18.5-23.9 \mathrm{~kg} / \mathrm{m}^{2}$ (normal weight), $24.0-27.9 \mathrm{~kg} / \mathrm{m}^{2}$ (overweight), and $\geq 28.0 \mathrm{~kg} / \mathrm{m}^{2}$ (obesity). Abdominal obesity was defined as follows: WHR $\geq 0.9$ for males and $\geq 0.85$ for females. ${ }^{11}$

\section{Statistical analysis}

All the statistical analyses were performed by SPSS 19.0 (IBM Corporation, SPPS Inc, Chicago, IL, USA). The Kolmogorov-Smirnov test was used to determine the normality of distributions. Continuous variables were presented as mean $\pm \mathrm{SD}$ or percentiles, while categorical variables were presented as percentages. Student's $t$-test, Mann-Whitney $U$-test, or chi-squared test was used to compare the data between participants with normal cognition and participants with cognitive impairment as appropriate. Univariate logistic regression models and multivariate logistic regression models were performed to explore the relationship between BMI or abdominal obesity and cognitive impairment. The results were considered significant when $P<0.05$.

\section{Results \\ Baseline characteristics}

A total of 1,100 elderly people including 568 men and 532 women aged 60-98 years (median age 79 years) were enrolled in this study. One hundred and eighty-five (16.8\%) people were diagnosed with cognitive impairment. The mean BMI was $23.23 \pm 3.65 \mathrm{~kg} / \mathrm{m}^{2}$ and the median WHR was $0.82(0.78,0.86)$. A total of $105(9.5 \%)$ participants were classified as obese and $206(18.7 \%)$ participants were classified as abdominal obese. The numbers of patients diagnosed 
with diabetes, hypertension, and hypercholesterolemia were 325 (29.5\%), 383 (34.8\%), and 79 (7.2\%), respectively. Baseline characteristics of participants are presented in Table 1.

\section{Characteristics between participants with normal cognition and participants with cognitive impairment}

The characteristics between participants with normal cognition and participants with cognitive impairment are displayed in Table 2. The median score of MMSE scale in the cognitive impairment group was much lower than that in the normal cognition group (13 vs $27, P<0.001)$. The median age of participants with cognitive impairment was significantly older than that of participants with normal cognition ( 82 vs 78 years, $P<0.001$ ). The mean BMI in the cognitive impairment group was relatively lower than that in the normal cognition group ( $22.43 \mathrm{vs} 23.40 \mathrm{~kg} / \mathrm{m}^{2}, P=0.001$ ). And the BMI categories were significantly different between groups. Although there were no significant differences in the waist and WHR between the two groups, the proportion of participants with abdominal obesity in the cognitive

Table I Baseline characteristics of participants

\begin{tabular}{|c|c|}
\hline Characteristics & $\begin{array}{l}\text { Mean } \pm \text { SD or P50 (P25, P75) } \\
\text { or number (percentage) }\end{array}$ \\
\hline Age (years) & $79(73,83)$ \\
\hline Male, n (\%) & $568(5 \mathrm{I} .6)$ \\
\hline \multicolumn{2}{|l|}{ Education level, n (\%) } \\
\hline Middle school and above & $292(26.5)$ \\
\hline Primary school & $384(34.9)$ \\
\hline Illiteracy & $424(38.5)$ \\
\hline BMI $\left(\mathrm{kg} / \mathrm{m}^{2}\right)$ & $23.23 \pm 3.65$ \\
\hline \multicolumn{2}{|l|}{ BMI category $\left(\mathrm{kg} / \mathrm{m}^{2}\right), \mathrm{n}(\%)$} \\
\hline $18.5-23.9$ & $575(52.2)$ \\
\hline$<18.5$ & $93(8.4)$ \\
\hline $24.0-27.9$ & $327(29.7)$ \\
\hline$\geq 28.0$ & $105(9.5)$ \\
\hline Waist (cm) & $73(67,8 \mathrm{I})$ \\
\hline Waist-hip ratio & $0.82(0.78,0.86)$ \\
\hline Abdominal obesity, n (\%) & $206(18.7)$ \\
\hline Smoking, n (\%) & $278(25.2)$ \\
\hline Drinking, n (\%) & $207(18.8)$ \\
\hline Diabetes, n (\%) & $325(29.5)$ \\
\hline Hypertension, n (\%) & $383(34.8)$ \\
\hline Hypercholesterolemia, n (\%) & $79(7.2)$ \\
\hline Cognitive impairment, $\mathrm{n}(\%)$ & $185(16.8)$ \\
\hline MMSE score & $26(23,28)$ \\
\hline
\end{tabular}

Abbreviations: BMI, body mass index; MMSE, Mini-Mental State Examination. impairment group was significantly greater than that in the normal cognition group $(25.4 \%$ vs $17.4 \%, P=0.011)$.

\section{Relationship between BMI and cognitive impairment}

Univariate logistic regression analysis showed that overweight $\left(\mathrm{BMI}=24.0-27.9 \mathrm{~kg} / \mathrm{m}^{2}\right)$ was significantly associated with a lower risk of cognitive impairment (OR $=0.439,95 \%$ $\mathrm{CI}=0.291-0.664, P<0.001)$. And this association remained significant after adjusting for some conventional risk factors. As demonstrated in Table 3, overweight remained significantly associated with a lower risk of cognitive impairment after adjusting for age, gender, smoking, drinking, education level, hypercholesterolemia, hypertension, and diabetes $(\mathrm{OR}=0.458,95 \% \mathrm{CI}=0.298-0.703, P<0.001)$. While underweight (BMI $<18.5 \mathrm{~kg} / \mathrm{m}^{2}$ ) and obesity (BMI $\geq 28.0 \mathrm{~kg} / \mathrm{m}^{2}$ ) were not significantly associated with cognitive impairment (both $P>0.1$ ) when using normal weight $\left(\mathrm{BMI}=18.5-23.9 \mathrm{~kg} / \mathrm{m}^{2}\right)$ as the reference.

\section{Relationship between abdominal obesity and cognitive impairment}

The association between abdominal obesity and cognitive impairment is shown in Table 4. In the univariate logistic regression model, abdominal obesity (defined by WHR cutoffs) was significantly associated with a higher risk of cognitive impairment $(\mathrm{OR}=1.619,95 \% \mathrm{CI}=1.116-2.350$, $P=0.011)$. In the multivariate logistic model, abdominal obesity remained significantly associated with a higher risk of cognitive impairment after adjusting for lifestyle risk factors including drinking and smoking $(\mathrm{OR}=1.619,95 \%$ $\mathrm{CI}=1.113-2.354, P=0.012)$. Similarly, abdominal obesity was significantly associated with a higher risk of cognitive impairment independent of other metabolic diseases such as hypercholesterolemia, hypertension, and diabetes (OR=1.667, 95\% CI=1.139-2.438, $P=0.008)$. Even after adjustment for age, education level, hypercholesterolemia, hypertension, and diabetes, abdominal obesity remained significantly associated with an increased risk of cognitive impairment ( $\mathrm{OR}=1.532,95 \% \mathrm{CI}=1.037-2.263, P=0.032)$.

\section{Discussion}

The relationship between obesity and cognitive impairment has been a controversial subject for many years. The present study demonstrated that overweight defined by BMI categories was significantly associated with a lower risk of cognitive impairment, while abdominal obesity defined by WHR cutoffs was significantly associated with a higher risk 
Table 2 Characteristics between participants with normal cognition and participants with cognitive impairment

\begin{tabular}{|c|c|c|c|}
\hline Variables & Normal cognition $(\mathrm{N}=9 \mid 5)$ & Cognitive impairment $(\mathrm{N}=\mid \mathbf{8 5})$ & $P$-value \\
\hline Age (years) & $78.00(72.00,83.00)$ & $82.00(77.50,85.50)$ & $<0.001$ \\
\hline Male, n (\%) & $480(52.5)$ & $88(47.6)$ & 0.225 \\
\hline Education level, n (\%) & & & 0.051 \\
\hline Middle school and above & $244(26.7)$ & $48(25.9)$ & \\
\hline Primary school & $306(33.4)$ & $78(42.2)$ & \\
\hline Illiteracy & $365(39.9)$ & 59 (31.9) & \\
\hline BMI $\left(\mathrm{kg} / \mathrm{m}^{2}\right)$ & $23.40 \pm 3.64$ & $22.43 \pm 3.56$ & 0.001 \\
\hline BMI category $\left(\mathrm{kg} / \mathrm{m}^{2}\right), \mathrm{n}(\%)$ & & & 0.001 \\
\hline $18.5-23.9$ & $458(50.1)$ & $117(63.2)$ & \\
\hline$<18.5$ & $74(8.1)$ & $19(10.3)$ & \\
\hline $24.0-27.9$ & $294(32.1)$ & $33(17.8)$ & \\
\hline$\geq 28.0$ & $89(9.7)$ & $16(8.6)$ & \\
\hline Waist (cm) & $73.00(67.00,81.00)$ & $72.00(65.00,79.50)$ & 0.071 \\
\hline Waist-hip ratio & $0.82(0.78,0.85)$ & $0.82(0.78,0.86)$ & 0.092 \\
\hline Abdominal obesity, n (\%) & $159(17.4)$ & $47(25.4)$ & 0.011 \\
\hline Smoking, n (\%) & $233(25.5)$ & $45(24.3)$ & 0.745 \\
\hline Drinking, n (\%) & $182(19.9)$ & $25(13.5)$ & 0.043 \\
\hline $\mathrm{TC}(\mathrm{mmol} / \mathrm{L})$ & $4.18 \pm 1.09$ & $4.19 \pm 1.11$ & 0.915 \\
\hline TG (mmol/L) & I.18 $(0.85,1.6 \mathrm{I})$ & I.12 $(0.83,1.58)$ & 0.302 \\
\hline LDL-C (mmol/L) & $2.49 \pm 0.91$ & $2.43 \pm 0.96$ & 0.392 \\
\hline HDL-C (mmol/L) & $1.33(1.08,1.62)$ & $1.36(1.04,1.63)$ & 0.979 \\
\hline Hypercholesterolemia, n (\%) & $61(6.7)$ & $18(9.7)$ & 0.141 \\
\hline Hypertension, n (\%) & $307(33.6)$ & $76(4 I . I)$ & 0.050 \\
\hline Diabetes, n (\%) & $265(29.0)$ & $60(32.4)$ & 0.345 \\
\hline MMSE score & $27(25,28)$ & $13(9,16)$ & $<0.001$ \\
\hline
\end{tabular}

Note: Data are shown as mean \pm SD or P50 (P25, P75) or number (percentage).

Abbreviations: BMI, body mass index; HDL-C, high-density lipoprotein cholesterol; LDL-C, low-density lipoprotein cholesterol; MMSE, Mini-Mental State Examination; TC, total cholesterol; TG, triglyceride.

of cognitive impairment in the Chinese elderly even after adjusting for sociodemographic, lifestyle, and health-related comorbid factors.

Our findings are consistent with several previous studies, which reported that overweight in late life was associated with a reduced risk of dementia. Atti et al investigated the relationship between late-life BMI and dementia incidence in 1,255 subjects aged 75 years and older in their 9-year follow-up study and revealed that subjects who were overweight $\left(\mathrm{BMI} \geq 25.0 \mathrm{~kg} / \mathrm{m}^{2}\right)$ had a lower risk of developing dementia than subjects with normal weight $\left(\mathrm{BMI}=20.0-24.9 \mathrm{~kg} / \mathrm{m}^{2}\right)$ $(\mathrm{HR}=0.75,95 \% \mathrm{CI}=0.59-0.96) .{ }^{12}$ This study also showed that there was no difference in the risk of dementia between subjects with obesity and subjects with normal weight. Ghaderpanahi et al explored the association between BMI and the risk of dementia in 108 participants aged 80 years and older in a cross-sectional study and showed that overweight $\left(\mathrm{BMI}=25.0-29.9 \mathrm{~kg} / \mathrm{m}^{2}\right)$ was an independent and significant protective factor against dementia risk $(\mathrm{OR}=0.24,95 \%$ $\mathrm{CI}=0.06-0.93) .{ }^{13}$ On the other hand, some studies revealed that midlife overweight and obesity were associated with a higher risk of dementia. ${ }^{14}$ The potential mechanisms linking overweight and cognitive impairment are not entirely clear. Two possible mechanisms might explain the beneficial role of overweight on cognitive impairment in late life. First, the hormone leptin, which is mainly secreted by the adipose tissue, might play a role as a cognitive enhancer. By regulating hippocampal synaptic plasticity and amyloid $\beta$-processing, leptin has been found to improve learning and memory performance in rodents. ${ }^{15,16}$ Second, individuals who are overweight have a lower mortality risk than individuals who are underweight or with normal weight in the elderly. Thus, it seems that overweight is indicative of a better health status compared with normal weight or underweight in late life. ${ }^{17}$ While the increased risk of cognitive impairment in subjects with midlife overweight and obesity could be explained by the 
Table 3 Association of body mass index with cognitive impairment

\begin{tabular}{|c|c|c|c|}
\hline Adjustment & OR & $95 \% \mathrm{Cl}$ & $P$-value \\
\hline \multicolumn{4}{|c|}{ Model I $\left(\mathrm{kg} / \mathrm{m}^{2}\right)$} \\
\hline $18.5-23.9$ & I & & \\
\hline$<18.5$ & 1.005 & $0.584-|.73|$ & 0.985 \\
\hline $24.0-27.9$ & 0.439 & $0.29 I-0.664$ & $<0.001$ \\
\hline$\geq 28.0$ & 0.704 & $0.398-1.244$ & 0.227 \\
\hline \multicolumn{4}{|c|}{ Model $2\left(\mathrm{~kg} / \mathrm{m}^{2}\right)$} \\
\hline $18.5-23.9$ & I & & \\
\hline$<18.5$ & 0.877 & $0.50 I-1.535$ & 0.645 \\
\hline $24.0-27.9$ & 0.450 & $0.296-0.685$ & $<0.001$ \\
\hline$\geq 28.0$ & 0.740 & $0.4 \mid 4-1.321$ & 0.308 \\
\hline \multicolumn{4}{|c|}{ Model $3\left(\mathrm{~kg} / \mathrm{m}^{2}\right)$} \\
\hline $18.5-23.9$ & I & & \\
\hline$<18.5$ & 0.857 & $0.486-1.510$ & 0.592 \\
\hline $24.0-27.9$ & 0.458 & $0.300-0.698$ & $<0.001$ \\
\hline$\geq 28.0$ & 0.708 & $0.394-1.270$ & 0.247 \\
\hline \multicolumn{4}{|c|}{ Model $4\left(\mathrm{~kg} / \mathrm{m}^{2}\right)$} \\
\hline $18.5-23.9$ & I & & \\
\hline$<18.5$ & 1.033 & $0.595-1.793$ & 0.907 \\
\hline $24.0-27.9$ & 0.439 & $0.289-0.667$ & $<0.001$ \\
\hline$\geq 28.0$ & 0.732 & $0.4|2-1.30|$ & 0.288 \\
\hline \multicolumn{4}{|c|}{ Model $5\left(\mathrm{~kg} / \mathrm{m}^{2}\right)$} \\
\hline $18.5-23.9$ & 1 & & \\
\hline$<18.5$ & 0.876 & $0.493-1.556$ & 0.651 \\
\hline $24.0-27.9$ & 0.458 & $0.298-0.703$ & $<0.001$ \\
\hline$\geq 28.0$ & 0.758 & $0.419-1.370$ & 0.359 \\
\hline
\end{tabular}

Notes: Model I: no adjustment; model 2: adjust for age, gender; model 3: adjust for age, gender, drinking, smoking, education level; model 4: adjust for hypercholesterolemia, hypertension, diabetes; model 5: adjust for age, gender, smoking, drinking, education level, hypercholesterolemia, hypertension, diabetes.

fact that a higher BMI in midlife is usually associated with cardiovascular and metabolic risk factors which are related to an increased risk of cognitive impairment. ${ }^{18,19}$

Another finding of the present study is that abdominal obesity is associated with an increased risk of cognitive impairment. Liu et al showed that central obesity (defined by WHR $<0.9$ for males and $<0.85$ for females) was significantly associated with a higher risk of cognitive impairment in 491 subjects aged 70 years and older $(\mathrm{OR}=1.980,95 \%$ $\mathrm{CI}=1.129-3.472) .{ }^{20}$ Luchsinger et al revealed that a higher WHR was related to a higher risk of late-onset Alzheimer's disease (HR of the fourth quartile compared to the first $=2.5$, 95\% CI $=1.3-4.7$ ) after adjustment for conventional risk factors. ${ }^{21}$ Abdominal obesity is a typical characteristic of the body fat distribution among the Chinese population. Individuals with abdominal obesity usually have a higher body fat percentage than individuals with simple obesity. 22,23 Abdominal obesity is a component of metabolic syndrome, which also includes insulin resistance, hyperglycemia, dyslipidemia, and hypertension. ${ }^{24}$ Our results suggested that abdominal obesity was a risk factor of cognitive impairment independent of hypercholesterolemia, hypertension, and diabetes. The underlying mechanism may partly be explained by insulin resistance. Recent studies have shown that insulin has the ability to regulate neural metabolism and trigger glucose uptake in the hippocampus and medial temporal lobe. By binding to insulin receptors, insulin plays an important part in hippocampal memory processing. Thus, insulin resistance in the hippocampus could impair spatial learning and synaptic plasticity. ${ }^{25,26}$

Another explanation is vascular endothelial damage and brain dysfunction. It has been proved that every component of metabolic syndrome is independently associated with vascular endothelial damage and thereby limits cerebrovascular blood flow. As a result, the risk of cognitive impairment increases, especially the risk of vascular cognitive impairment. ${ }^{27}$

In the present study, no significant association was found between underweight and cognitive impairment, which was in contrast to previous studies that revealed a significant association between underweight and an increased risk of dementia. ${ }^{28}$ One possible explanation for this inconsistency may be that elderly people who are underweight have a higher risk of death and thus cognitive impairment is probably underestimated. So we could not rule out the possibility that the lack of association between a low BMI and an increased risk of cognitive impairment in the present study is due

Table 4 Association of abdominal obesity with cognitive impairment

\begin{tabular}{|c|c|c|c|}
\hline Adjustment & OR & $95 \% \mathrm{Cl}$ & $P$-value \\
\hline No adjustment & 1.619 & $1.116-2.350$ & 0.011 \\
\hline Adjust for drinking, smoking & 1.619 & $1.113-2.354$ & 0.012 \\
\hline Adjust for age, education level & 1.473 & $1.006-2.156$ & 0.046 \\
\hline Adjust for hypercholesterolemia, hypertension, diabetes & 1.667 & $1.139-2.438$ & 0.008 \\
\hline Adjust for age, education level, hypercholesterolemia, hypertension, diabetes & 1.532 & $1.037-2.263$ & 0.032 \\
\hline
\end{tabular}


to the underestimation of cognitive impairment incidence among the dead.

This study may have several potential limitations. First, this is a cross-sectional study. Only correlations rather than causal relationships can be established due to the study design. Although we adjusted some conventional sociodemographic, lifestyle, and health-related comorbid factors, we cannot adjust the other unmeasured confounding factors such as APOE4 genotype, diet, and drugs. Second, this is a single-center study and all the participants are from the same tertiary hospital in southwest China, so we may not generalize the results to other demographic groups. Third, the association between obesity and different types of cognitive impairment such as vascular cognitive impairment and Alzheimer's disease is not explored due to insufficient data in this study. Further multicentered, prospective cohort studies enrolled participants with different demographic characteristics are needed.

\section{Conclusion}

Overweight based on BMI categories is associated with a lower risk of cognitive impairment in the Chinese elderly, while abdominal obesity defined by WHR cutoffs is associated with a higher risk of cognitive impairment independent of conventional sociodemographic, lifestyle, and health-related comorbid factors. The results of this study are of value for the prevention of cognitive impairment. Further multicentered, prospective cohort studies with a long-term follow-up are needed.

\section{Acknowledgments}

The authors thank the participants or caregivers who took part in this study and the research staff who helped to conduct this work. This study was supported by grants from the Key Project of Chongqing Municipal Health Bureau (2016ZDXM005), Key-Project of Social Undertakings and People's Livelihood Security of Chongqing Science \& Technology Commission (cstc2017shms-zdyfX0009), Subproject of National Science and Technology Supporting Program of the Ministry of Science and Technology of China (2015BAI06B04), and National Key Clinical Specialties Construction Program of China (No [2013] 544).

\section{Disclosure}

The authors report no conflicts of interest in this work.

\section{References}

1. Hugo J, Ganguli M. Dementia and cognitive impairment: epidemiology, diagnosis, and treatment. Clin Geriatr Med. 2014;30(3):421-442.
2. Livingston G, Sommerlad A, Orgeta V, et al. Dementia prevention, intervention, and care. Lancet. 2017;390(10113):2673-2734.

3. General Administration of sport of China. National physique monitoring Bulletin; 2014. Available from: http://www.sport.gov.cn/n16/n1077/ n1227/7328132.html/. Accessed November 25, 2015.

4. Rosengren A, Skoog I, Gustafson D, Wilhelmsen L. Body mass index, other cardiovascular risk factors, and hospitalization for dementia. Arch Intern Med. 2005;165(3):321-326.

5. Whitmer RA, Gunderson EP, Barrett-Connor E, Quesenberry CP Jr, Yaffe K. Obesity in middle age and future risk of dementia: a 27 year longitudinal population based study. BMJ. 2005;330(7504):1360-1362.

6. Businaro R, Ippoliti F, Ricci S, Canitano N, Fuso A. Alzheimer's disease promotion by obesity: induced mechanisms-molecular links and perspectives. Curr Gerontol Geriatr Res. 2012;2012:986823:1-13.

7. Luchsinger JA, Patel B, Tang MX, Schupf N, Mayeux R. Measures of adiposity and dementia risk in elderly persons. Arch Neurol. 2007; 64(3):392-398.

8. Kivipelto M, Ngandu T, Fratiglioni L, et al. Obesity and vascular risk factors at midlife and the risk of dementia and Alzheimer disease. Arch Neurol. 2005;62(10):1556-1560.

9. Fitzpatrick AL, Kuller LH, Lopez OL, et al. Midlife and late-life obesity and the risk of dementia: cardiovascular health study. Arch Neurol. 2009; 66(3):336-342.

10. Katzman R, Zhang MY, Ouang-Ya-Qu, et al. A Chinese version of the Mini-Mental State Examination; impact of illiteracy in a Shanghai dementia survey. J Clin Epidemiol. 1988;41(10):971-978.

11. Zhou B. Predictive values of body mass index and waist circumference to risk factors of related diseases in Chinese adult population. Chin J Epidemiol. 2002;23:5-10.

12. Atti AR, Palmer K, Volpato S, Winblad B, De Ronchi D, Fratiglioni L. Late-life body mass index and dementia incidence: nine-year follow-up data from the Kungsholmen Project. J Am Geriatr Soc. 2010;56(1): $111-116$.

13. Ghaderpanahi M, Fakhrzadeh H, Sharifi F, et al. Association between late-life body mass index, waist circumference, and dementia: Kahrizak elderly study. J Am Geriatr Soc. 2012;60(1):173-174.

14. Emmerzaal TL, Kiliaan AJ, Gustafson DR. 2003-2013: a decade of body mass index, Alzheimer's disease, and dementia. J Alzheimers Dis. 2015;43(3):739-755.

15. Harvey J, Solovyova N, Irving A. Leptin and its role in hippocampal synaptic plasticity. Prog Lipid Res. 2006;45(5):369-378.

16. Oomura Y, Hori N, Shiraishi T, et al. Leptin facilitates learning and memory performance and enhances hippocampal CA1 long-term potentiation and CaMK II phosphorylation in rats. Peptides. 2006;27(11): 2738-2749.

17. Dahl AK, Fauth EB, Ernsth-Bravell M, Hassing LB, Ram N, Gerstof D. Body mass index, change in body mass index, and survival in old and very old persons. J Am Geriatr Soc. 2013;61(4):512-518.

18. Cheng G, Huang C, Deng H, Wang H. Diabetes as a risk factor for dementia and mild cognitive impairment: a meta-analysis of Longitudinal studies. Intern Med J. 2012;42(5):484-491.

19. Whitmer RA, Sidney S, Selby J, Johnston SC, Yaffe K. Midlife cardiovascular risk factors and risk of dementia in late life. Neurology. 2005; 64(2):277-281.

20. Liu Z, Yang H, Chen S, Cai J, Huang Z. The association between body mass index, waist circumference, waist-hip ratio and cognitive disorder in older adults. J Public Health. 2018;278(9).

21. Luchsinger JA, Cheng D, Tang MX, Schupf N, Mayeux R. Central obesity in the elderly is related to late-onset Alzheimer disease. Alzheimer Dis Assoc Disord. 2012;26(2):101-105.

22. Li X, Wu J, Zuo SY, et al. Epidemiological characteristics of central obesity. Chin J Gerontol. 2012;32:4015-4018.

23. Wang W, Wang K, Li T, et al. [A discussion on utility and purposed value of obesity and abdomen obesity when body mass index, waist circumference, waist to hip ratio used as indexes predicting hypertension and hyper-blood glucose]. Zhonghua Liu Xing Bing Xue Za Zhi. 2002;23(1):16-19. Chinese. 
24. Capuron L, Su S, Miller AH, et al. Depressive symptoms and metabolic syndrome: is inflammation the underlying link? Biol Psychiatry. 2008; 64(10):896-900.

25. Cholerton B, Baker LD, Craft S. Insulin, cognition, and dementia. Eur J Pharmacol. 2013;719(1-3):170-179.

26. Grillo CA, Piroli GG, Lawrence RC, et al. Hippocampal insulin resistance impairs spatial learning and synaptic plasticity. Diabetes. 2015; 64(11):3927-3936.
27. Arshad N', Lin TS, Yahaya MF. Metabolic syndrome and its effect on the brain: possible mechanism. CNS Neurol Disord Drug Targets. 2018;17(8):595-603.

28. Nourhashémi F, Deschamps V, Larrieu S, et al; PAQUID study. Personnes Agées Quid. Body mass index and incidence of dementia: the PAQUID study. Neurology. 2003;60(1):117-119.

\section{Publish your work in this journal}

Clinical Interventions in Aging is an international, peer-reviewed journal focusing on evidence-based reports on the value or lack thereof of treatments intended to prevent or delay the onset of maladaptive correlates of aging in human beings. This journal is indexed on PubMed Central, MedLine,

\section{Dovepress}

CAS, Scopus and the Elsevier Bibliographic databases. The manuscript management system is completely online and includes a very quick and fair peer-review system, which is all easy to use. Visit http://www.dovepress. $\mathrm{com} /$ testimonials.php to read real quotes from published authors. 